\title{
TITLE:
}

\section{STUDIES ON THE EGGS AND LARVAE OF THE JAPANESE GASTROPODS(4)}

AUTHOR(S):

Habe, Tadashige

\section{CITATION:}

Habe, Tadashige. STUDIES ON THE EGGS AND LARVAE OF THE JAPANESE

GASTROPODS(4). PUBLICATIONS OF THE SETO MARINE BIOLOGICAL LABORATORY 1953, 3(2): 161-167

ISSUE DATE:

1953-12-20

URL:

http://hdl.handle.net/2433/174472

RIGHT: 


\title{
STUDIES ON THE EGGS AND LARVAE OF THE JAPANESE GASTROPODS $(4)^{*}$
}

\author{
TADASHIGE HABE \\ Zoological Institute and Seto Marine Biological Laboratory, \\ Kyoto University \\ With 3 Text-figures
}

The writer published in 1944 three papers on the eggs and larvae of some Japanese gastropods in "the Japanese Journal of Malacology" (Venus), Vol. 13. The present report deals with Serpulorbis imbricata, Brochina glabella, Amalthea conica, Amalthea (Antisabia) foliacea, Crepidula gravispinosa and Rosenia castanea.

I express here my hearty thanks to Dr. Taku KomaI for his kind guidance and incessant encouragement during the course of this study.

\section{Serpulorbis imbricata (DUNKER)}

(Figs. 1, a-h)

The species is very common on rocks between tidal marks on the beach near the Seto Marine Biological Laboratory. The breeding takes place in May and June. The egg capsule (Figs. 1-3) is ovate, numbering from 20 to 30 in each mass which is attached to the inside of the tube of the shell at its attenuated extremity by a short peduncle; it measures 3 to $3.5 \mathrm{~mm}$ in length and 1.1 to $1.5 \mathrm{~mm}$ in breadth. The capsular wall is thin and transparent, so that the eggs are clearly seen through. The eggs are cream yellow, spherical and $0.24 \mathrm{~mm}$ in diameter. Each capsule contains 70-80 eggs (Fig. 1c) of which some develop into veliger larvae eating the rest of eggs. The veliger (Fig. 1f) is about $0.4 \mathrm{~mm}$ long and bears a shell around the posterior part of the body and a bilobed ciliated velum on the anterior end. The velum is provided with a pair of minute tentacles. Each tentacle has a minute eye spot at the swollen base. The foot is small and triangular, and has an otocyst at the base. The whorl of the shell increases with development. In the veliger (Figs. 1e, g) of $0.44 \mathrm{~mm}$ in shell length, the shell is pale yellow and consists of two distinct whorls and has a

* Contributions from the Seto Marine Biological Laboratory, No. 214.

Publ. Seto Mar. Biol. Lab., III (2), 1953. (Article 15) 
narrow umbilicus. The shell axis is tinted pale orange. The lobes have attained a large size, slightly constricted in the middle and with long cilia bordering them. The tentacles also have become prominent. The liver is orange or browish orange in colour, visible through the translucent shell. The mouth part and foot are purplish. The foot
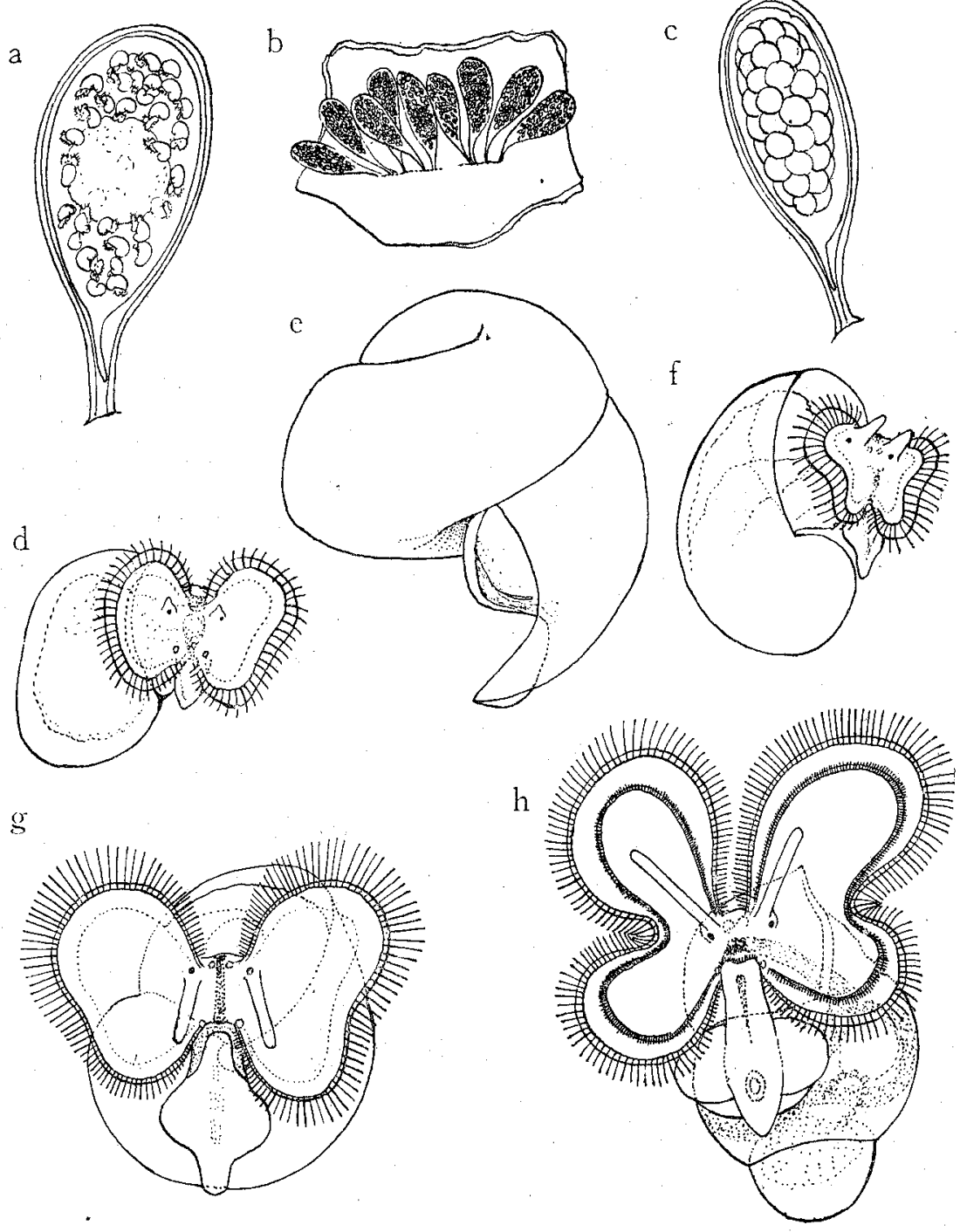

Fig. 1. Serpulorbis imbricata (DUNKER). a, egg capsule, containing veligers and a nurse mass; $b$, egg capsules adhered to the inside of shell of the parent; $c$, egg capsule containing eggs; $d$, veliger, $0.32 \mathrm{~mm}$ across; $e$, larval shell, $0.44 \mathrm{~mm}$ across ; $f$, veliger, $0.42 \mathrm{~mm}$ in shell length; $g$, veliger, $0.44 \mathrm{~mm}$ in shell length; $h$, veliger, $0.63 \mathrm{~mm}$ in shell length. 
is produced laterally into two processes and carries a small and thin operculum. In the stage when the shell measures $0.63 \mathrm{~mm}$ in length and $0.45 \mathrm{~mm}$ in breadth, the veliger (Fig. 1h) hatches out. The larva has the umbilicated shell with $3 \frac{1}{2}$ whorls and four lobed velum bordered by long cilia. The upper lobes are larger than the lower. The foot has considerably developed, and bears the thin operculum on the back.

\section{Brochina glabella A. ADAMS}

(Figs. 2, a-d)

The creeping larva (Figs. 2, a, b) measures $0.58-0.6 \mathrm{~mm}$ in shell length and has a spiral embryonic shell with about $1 \frac{1}{2}$ whorls. The last body whorl is uncoiled and detached from the penultimate one. The spiral part of the shell is smooth, while the uncoiled part is faintly marked with growth lines. The bilobed velum on the lateral sides of the head has been reduced. The shell (Fig. 2c), $0.9 \mathrm{~mm}$ in length, still retains the posterior spiral part. This part is empty, however and the animal occupies only the anterior straight part; there is a distict septum between the two parts. When the shell (Fig. 2d) becomes more than $1 \mathrm{~mm}$ in length, the spiral part of shell has been detached, and the animal completes metamorphosis.

This small snail with a tubular shell is common under stones between the tidal marks near Shirahama, Wakayama Pref.

\section{Amalthea conica (SCHUMACHER)}

(Figs. 2, e-j)

The eggs and larvae of this species have been described and figured by S. SuzukI (1935) as of Hipponyx pilosus. This species is very common on the shell of some gastropods such as Haliotis and Astraea.

The adult spawns in spring and summer. The egg capsule (Fig. 2c) is ovate and attached to the substratum by a short stalk, and covered by the parent. Three to six egg capsules are united by the stalk into a common stem. Each capsule contains about 30 eggs which are yellowish white and $0.45 \mathrm{~mm}$ in diameter. Besides the eggs many yolk fragments are observed in the capsule. These may be a kind of nurse materials. The larva, $0.58 \mathrm{~mm}$ long (Figs. $2 \mathrm{f}, \mathrm{g}$ ), is ovate, rounded anteriorly, attenuated posteriorly and has a small circular velum bordered by long cilia, and provided with eye spots; a small triangular spot is also present. The shell is thin, cup-like, and covers the posterior part of this veliger. In the post veliger stage, the shell (Figs. 2h, i) is brownish and has $1 \frac{1}{2}$ whorls, marked with about twenty ciliated radial threads. The velum is bilobed; the tentacles are long and with eyes at the base. The foot is well developed, purplish in colour, and carries an operculum on the 


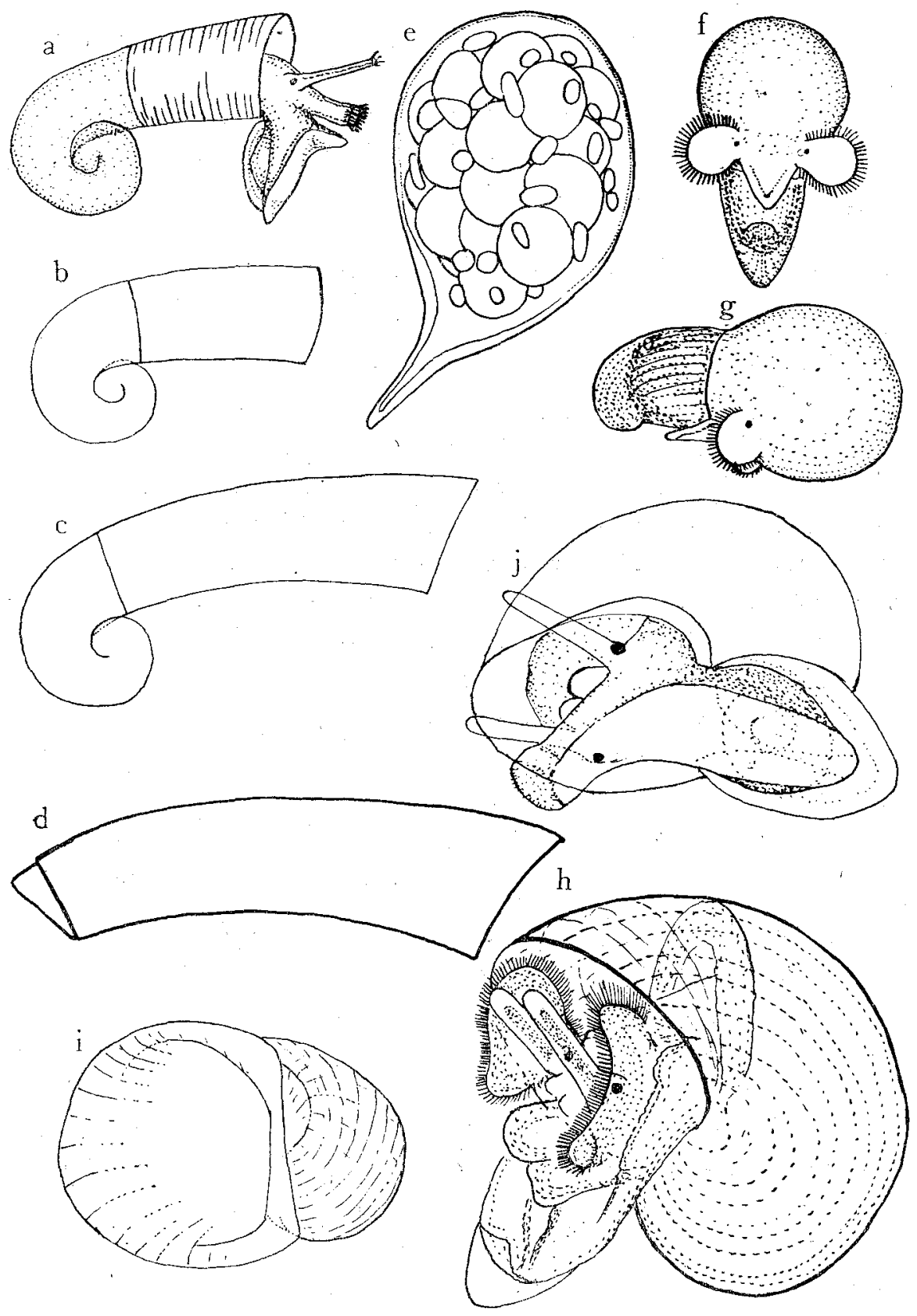

Fig. 2. Brochina glabella A. ADAMS $(a-d)$, Amalthea conica (SCHUMA.CHER) $(e-j)$.

$a$, young creeping animal; $b$, young shell, $0.6 \mathrm{~mm}$ in length, still retaining the embryonic shell; $c$, young shell, $0.9 \mathrm{~mm}$ in length; $d$, immature shell, $1.5 \mathrm{~mm}$ in length; $e$, egg capsule, containing eggs and yolk fragments; $f, g$, veliger, $0.58 \mathrm{~mm}$ across; $h, i$, veliger; $j$, young creeping larva. 
dorsal side. The newly hatched larva (Fig. $2 \mathrm{j}$ ) acquires a radula in the mouth, and has lost the operculum before long.

\section{Amalthea (Antisabia) foliacea (QUOY et GAIMARD)}

(Figs. 3, a-b)

This species is very common in crevices of rocks between the tidal marks near Shirahama. Breeding takes place in summer, from June to August. The egg capsule (Figs. 3a, b) is thin, transparent, ovate in shape, and $2.4 \mathrm{~mm}$ long; it is fixed to the substratum by its stalk which is $2.2 \mathrm{~mm}$ long, and covered by the parent. About 15 capsules are laid by one individual. Each capsule contains about 15 eggs, which are $0.3 \mathrm{~mm}$ in diameter and pale yellow. The embryo, $0.45 \mathrm{~mm}$ long, has cilia on the whole surface and a thin cup-shaped shell in the posterior part. The shell (Fig. 3c) is $0.42 \mathrm{~mm}$ long, thin, transparent, pale yellow in colour and has one-fourth whorl. The beginning whorl is smooth, and the remaining part has about twenty threads which are densely sprinkled with minute granules. The velum consists of two rounded lobes, bordered by long cilia. The tentacles are rather long and provided with eyes at the base. The foot is triangular, tapering posteriorly, and bears an operculum on the dorsal lobes of the foot. The full-grown veliger (Fig. 3d) has a shell about $0.5 \mathrm{~mm}$ in length. The shell consists of two whorls increasing rapidly in diameter. The growth lines on the surface are distinct. The animal is purplish in colour. The vela and tentacles are more enlarged. The operculum is still present.

\section{Crepidula gravispinosa KURODA et HABE}

(Figs. 3, e-i)

The species has been erroneously identified with Crepidula aculeata (GMELIN) of the Atlantic. It should be named Crepidula gravispinosa Kuroda et HABE. The animal is common on rocks near the tidal marks at Shirahama.

Spawning takes place from May to November. The eggs are contained in fanshaped capsules (Fig. 3e) are $1.5 \mathrm{~mm}$ across aud united in a branch by their stalks in a common stem fastened to the substratum. About five capsules make a cluster and are covered by the parent. The capsules are thin, transparent, and contain each from 15-20 eggs, which are $0.2 \mathrm{~mm}$ across and cream yellow in colour. The larval shell measures $0.4 \mathrm{~mm}$ in length and has $1 \frac{1}{2}$ whorls. With development the diameter of the whorl enlarges, and the sculpture with many ciliated threads becomes distinct. The bilobed velum is bordered by long cilia and provided with long tentacles bearing eyes near the base. The otocyst is also distinct. In the larva (Figs. $3, \mathrm{f}-\mathrm{h}$ ) with the shell $0.72 \mathrm{~mm}$ long and of two whorls has the velum more enlarged. The thin 


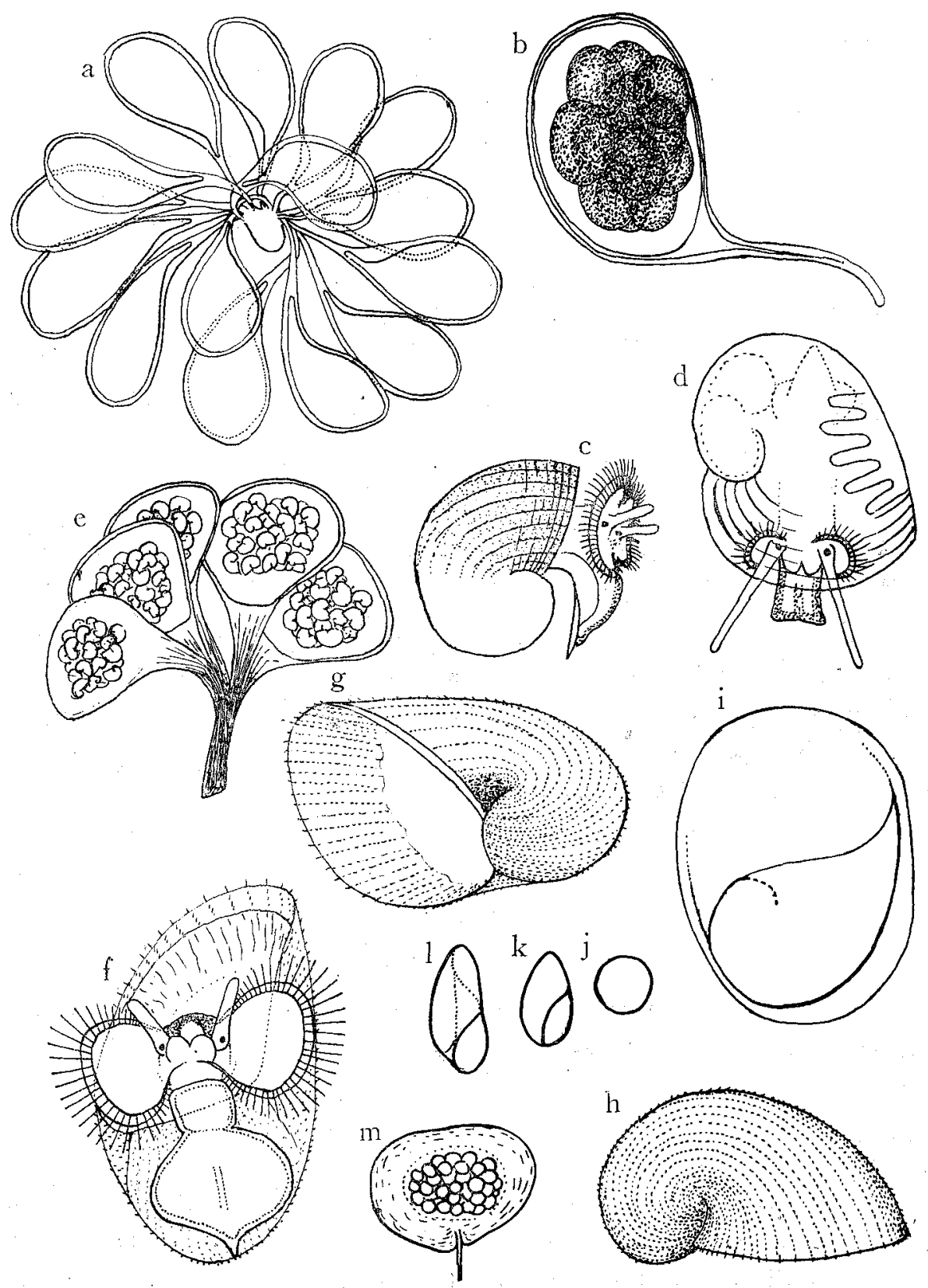

Fig. 3. Amalthea (Antisabia) foliacea (QUOY et GAIMARD) (a-b), Crepidula gravispinosa KURODA et HABE (e-i), Rosenia castanea (DALL) (j-m). $a$, a mass of egg capsules; $b$, egg capsule containing eggs ; $c$, veliger, $0.42 \mathrm{~mm}$ in shell length; $d$, veliger, $0.5 \mathrm{~mm}$ in shell length; $e$, a mass of egg capsules; $f$, veliger, $0.72 \mathrm{~mm}$ in shell length; $g, h$, young shell, $0.72 \mathrm{~mm}$ in length; $i$, young creeping shell; $j$, egg, $0.11 \mathrm{~mm}$ across; $k$, embryonic shell, $0.19 \mathrm{~mm}$ in length ; $l$, embryonic shell, $0.25 \mathrm{~mm}$ in length; $m$, egg capsule containing eggs. 
operculum is still retained on the dorsal lobes of foot; the radula has developed in the mouth part. In the larva of $1.2 \mathrm{~mm}$ in shell-length, metamorphsis already takes place; the velum has reduced and the radula becomes distinct.

\section{Rosenia castanea (DALL)}

(Figs. 3, j-m)

On July 2, 1944, Mr. Masuoki HoRikosi kindly sent the present specimens collected at Okitsu, Chiba Pref. and preserved in alcohol. One of the specimens had laid a mass of egg capsules among spines of Pseudocentrotus depressus. The egg capsules (Fig. $3 \mathrm{~m}$ ) measuring $1.2 \mathrm{~mm}$ in breadth and $1.0 \mathrm{~mm}$ in length are colourless, transparent, ovate, and attached to the spines of the host by the stalk. About fifty eggs were contained in the fluid within the capsule. The eggs (Fig. 3j) are spherical in shape, yellowish-white in colour and $0.11 \mathrm{~mm}$ across. The larvae (Figs. 3k, 1) in the capsule had transparent brownish shell with $1 \frac{1}{2}$ whorls, which is about $0.25 \mathrm{~mm}$ in length and $0.15 \mathrm{~mm}$ in breadth.

\section{REFERENCES}

GöTzE, E. 1938. Bau und Leben von Caecum glabrum (Montagu). Zool. Jahrb., Abt. Syst., vol. 71, pp. $55-122$.

ISHIKI, H. 1936. Sex-changes in Japanese slipper limpets, Crepidula aculeata and Crepidula walshi. Jour. Sci. Hiroshima Univ., Ser. B, Div. 1, vol. 4, pp. 91-99.

LEBOUR, M. V. 1932. The eggs and early larval stages of two commensal Gastropods. Stilifer stylifer and Odostomia eutimoides. Jour. Mar. Biol. Assoc., N. S., vol. 18, pp. 117-121.

1936. Notes on the eggs and larvae of some Plymouth Prosobranchs. Jour. Mar. Biol. Assoc., N. S., vol. 20, pp. 547-565.

1937. The eggs and larvae of the British Prosobranchs with special reference to those living in the plankton. Jour Mar Biol. Assoc., N. S., vol. 22, pp. 105-166.

OSTERGAARD, J. M. 1950. Spawning and development of some Hawaiian marine Gastropods. Pacific Science, vol. 4, pp. 75-115.

PEILE, A. J. 1935. Note on Amalthea lissa. Proc. Malac. Soc. London, vol. 21, p. 251.

SUZUKI, S. 1935. On the larval development of Crepidula pilosus Deshayes. Botany and Zoology, vol. 3, no. 6, pp. 1193-1195. (in Japanese)

THORSON, G. 1940. Studies on the egg masses and larval development of Gastropoda from the Iranian Gulf. Danish Sci. Invest. Iran, pt. 2, 159-236.

1946. Reproduction and larval development of Danish marine bottom invertebrates. Med. d. Komm. Danmark Fisk., Plankton, vol. 4, no. 1, pp. 1-523. 